\title{
25 Research Square \\ Effect of Lavender Oil on Nausea, Vomiting, and Anxiety in Pregnant Women: A Randomized Clinical Trial
}

\section{Azam Amzajerdi}

Tehran University of Medical Sciences

Maryam Keshavarz ( $\nabla$ keshavarz.m@iums.ac.ir)

Iran University of Medical Sciences

Ali Montazeri

ACECR

\section{Reza Bekhradi}

Barij Medicinal Plants Research Center

\section{Research Article}

Keywords: Lavender oil, nausea and vomiting, anxiety, pregnancy

Posted Date: July 8th, 2021

DOl: https://doi.org/10.21203/rs.3.rs-681694/v1

License: (c) (i) This work is licensed under a Creative Commons Attribution 4.0 International License. Read Full License 


\section{Abstract}

Objective: The present study was performed to determine whether lavender oil affects nausea-vomiting and anxiety in pregnant women.

Methodology: In a quasi-experimental study, sixty-six pregnant women in the 6th to 16th week of pregnancy with a range of mild to moderate nausea and vomiting were randomized into two groups; a Lavender and a control group ( $\mathrm{n}=33$ for each group). Twice a day (before rest in the afternoon and night sleep) for a week, samples in the intervention and control group inhaled Lavender and sesame oil, respectively. Every night before sleeping, the Rhodes nausea-vomiting questionnaire was completed by the subjects. In addition, Maternal State Anxiety (MSA) in mothers of two groups was measured by using the state anxiety scale before and on the seventh day of the intervention.

Results: Seven days after inhalation of Lavender oil, the overall mean score of Rhodes index and the severity of nausea and vomiting ( $p=0.008, p=0.032$, respectively), also the mean scores and severity of MSA in mothers of the Lavender group were significantly lower than the control group $(p=0.012$ and $\quad p=0.027$, respectively). According to the repeated measures analysis, the mean score of the Rhodes index was significantly decreased in the Lavender and control groups during one week $(p=$ 0.0001 and 0.004 , respectively).

Conclusion: This study presented evidence that Lavender aromatherapy could decrease nausea, vomiting, and anxiety in pregnant women. The findings can guide healthcare workers in providing aromatherapy to women throughout pregnancy.

\section{Introduction}

Nausea and vomiting of pregnancy (NVP) are common conditions with $50-80 \%$ prevalence for nausea and $50 \%$ vomiting (ACOG, 2018). Nausea has been reported to be responsible for $33 \%$ of all sick leave during pregnancy (Gray et al., 2018). NVP can significantly reduce pregnant women's quality of life and negatively affect daily activities, relationships with partners, parenting, occupation, and social functioning (Bustos et al., 2017, Gray et al., 2018). Studies have also highlighted the economic burden on women and society, mainly due to lost productivity and healthcare costs (ACOG, 2018, Gray et al., 2018, Matthews et al., 2015). In a cross-sectional multinational web-based study of 9113 pregnant women and new mothers, 73.5\% experienced nausea during pregnancy (Heitmann et al., 2015). Despite its high prevalence and the resulting social and economic problems, its definitive treatment has not been determined (Schrager et al., 2021).

There is little data on safety concerning risks of structural malformations for many medications (Parker et al., 2018). The teratogenic effects of using some drugs to control these symptoms have led to cautious prescribing and taking medications in the first trimester (Matthews et al., 2015). Most women preferred not to take medications, especially out of concern for these drugs' side effects on the fetus (Gray et al., 
2018). In one study, the respondents with nausea were administered standard medications and medicinal plants in $17.9 \%$ and $8.3 \%$, respectively (Heitmann et al., 2015).

Psychological conditions during gestation and their impact on perinatal outcomes are a matter of debate. However, one of the most prevalent conditions is anxiety, affecting approximately one-third of pregnant women at some point during gestation (Ravid et al., 2018). A large meta-analysis of 102 studies found a prevalence of antenatal anxiety ranging from $18.2 \%$ in the first trimester to $24.6 \%$ in the third trimester (Dennis et al., 2017). Anxiety may increase the risk of preterm birth and low birth weight infants (Dennis et al., 2017, Ravid et al., 2018). In addition, in a study conducted in the Netherlands, antenatal anxiety early in pregnancy significantly increased the risk for cognitive disorders in children at 14 and 15 years of age (Dennis et al., 2017).

Consequently, many women may turn to complementary and alternative medicine (CAM) as a natural and safe method to alleviate their symptoms (Heitmann et al., 2015). The prevalence of complementary and alternative medicine (CAM) use in pregnancy has been reported to range between $20 \%$ and $60 \%$ (Di Vito et al., 2021). Aromatherapy is one of the most popular CAM used by pregnant women (Di Vito et al., 2021) that uses essential oils to maintain and promote physical, psychological, and spiritual well-being (Ali et al., 2015, Hedaoo et al., 2019). Lavender oil has been introduced as the most often used oil at each trimester of pregnancy $(0.7 \%, 0.6 \%$, and $0.3 \%$, respectively) (Bishop et al., 2011$)$.

The positive effects of aromatherapy with Lavender on post-operative's nausea and vomiting (PONV) (Karaman et al., 2019), also after chemotherapy in patients with breast cancer have been reported (Ain et al., 2019). However, the Lavender had no significant effect on nausea after percutaneous nephrolithotomy (Amirhosseini et al., 2020). Using a combination of Lavender, Peppermint, Spearmint, and Ginger oil significantly affected PONV (Hodge et al., 2014). The study of the effect of only Lavender on NVP is limited. In one study, Lavender oil was more effective than Ginger aromatherapy (Rahayu \& Sugita, 2018). In another, Peppermint and Lavender's combination therapy reduced the severity of NVP, increased energy levels, and reduced fatigue in pregnant women (Ghani \& Ibrahim, 2013). The limitation of studies indicates the need for further research to definitive conclusions about the impact of Lavender aroma on NVP.

Lavender is one of the most popular essential oils for mental disorders and anxiety (López et al., 2017). Some researchers reported the positive effect of Lavender oil in anxiety conditions; dental anxiety (Arslan et al., 2020), bone marrow biopsy (Abbaszadeh et al., 2020), peripheral venous cannulation (Karaman et al., 2016), reduction of cortisol level in candidates for open-heart surgery (Hosseini et al., 2016), in highrisk postpartum women (Conrad \& Adams, 2012), postpartum blues (Amin et al., 2020), also during labor (Mirzaei et al., 2009). The results of a Systematic Review and Meta-analysis of randomized controlled trials showed that aromatherapy with Lavender might have positive effects on anxiety and its physiological manifestations (Kang et al., 2019).

The study of the effect of only Lavender on the anxiety of pregnancy is limited. In two studies, Lavender oil was one of the three possible oils to choose for inhalation in pregnancy (Igarashi and Fujita, 2010, 
Igarashi, 2013). One study evidence that aromatherapy massage with Lavender oil could significantly decrease stress and enhance immune function in pregnant women (Chen et al., 2017). Moreover, one study has reported that aromatherapy inhalation with foot-bath and Lavender alone could significantly decrease anxiety in pregnancy (Effati-Daryani et al., 2015).

Various researchers reported the association between anxiety with nausea and vomiting during pregnancy (Köken et al., 2008, Nikibakhsh et al., 2016, Beyazit et al., 2018); however, in a randomized control trial, the Mint oil positively reduced nausea and vomiting during pregnancy without any impact on state anxiety (Amzajerdi et al., 2019).

According to the Cochrane review, there is little evidence that non-pharmacological methods effectively reduced the NVP (Matthews et al., 2015). As a result, more studies need to approve this method as an effective method for pregnant women. The present study was designed to investigate the effects of a one-week Lavender oil on NVP and anxiety. It was; based on the hypothesis that Lavender improves nausea, vomiting, and anxiety in pregnancy.

\section{Materials And Methods}

\section{Study design}

This single-blind, semi-experimental study have been conducted from Jan 20 to Jun 15, 2015. The study samples were pregnant women referred to the prenatal care center of Baharloo teaching hospital, affiliated with Tehran University of Medical Sciences (TUMS) in Tehran, Iran.

\section{Sample size}

Considering that the present study's primary outcome was anxiety, nausea, and vomiting of pregnant women, to detect a significant difference among the two groups, a sample of 33 subjects per group was estimated. A study with such a sample size would have a power of $80 \%$ and a confidence level of $95 \%$ for considering attrition.

\section{Randomization and blinding}

On the first day, according to a coin throwing by a research assistant, the samples were placed in the control group and the next day in the Lavender group. Until the last day, to prevent contact mothers from each other, the participants were allocated every other day to one of the control or Lavender. Data gathering was done by a research assistant who was blind to the groups' assignment.

\section{Study population}

The study population included all pregnant women with NVP admitted to the prenatal care unit of the Baharloo teaching center in Tehran, Iran's capital city. Participants were pregnant women between 15 to 34 years old, with the gestational age of 6 to 16 week of pregnancy based on the first day of the last 
menstrual period or sonography of the first trimester who met the following criteria: a normal, single, and wanted pregnancy, mild to moderate nausea, and vomiting (according to Rhodes index), state anxiety scale less than 60 , no cold, physical, mental, and emotional recognized diseases, exposure to stressful events during the past three months, history of allergy to herbal drugs, olfactory disorders, use of anti-emetic or emetic drugs (herbal or chemical drugs) in the past 24 hours, and sedative drugs or other therapeutic measures such as vegetable oils according to their reporting. Exclusion criteria included crises and stressful events during the study, unwillingness to continue the study, absent regular use of aromatherapy (no using oil during two consecutive or non-consecutive days), the use of drugs or other complementary medicines that can reduce nausea, vomiting or anxiety.

\section{Intervention}

The researcher explained the purpose and procedure of the study to the mothers who had the inclusion criteria. Mothers were encouraged to ask any questions that they had concerning the research. We used a formal written paper through a generic consent form suggested and approved by the TUMS ethics committee. On the first day at the prenatal care unit, the mothers in both Lavender and control groups individually filled out a demographic questionnaire, Rhodes nausea-vomiting questionnaire, and state anxiety scale. All mothers received routine training on diminishing nausea, such as avoid foods, smells, activities, or similar situations that may exacerbate NVP (ACOG, 2018).

Aromatherapy was conducted seven days in both groups. Kashan Barij Esanse Pharmaceutical Company manufactured Lavender oil and placebo used in the present study. The oil was extracted from the flowering aerial parts of Lavender (Lavandula Angustifolia) and diluted with $10 \%$ concentration in odorless sesame base oil. Sesame oil was used in the control group as a placebo. Twice a day (before rest in the afternoon and night sleep) for a week, samples in the Lavender and control group inhaled Lavender and sesame oil, respectively. Each time, the samples dripped four drops of bottle content on cotton, kept them in $20 \mathrm{~cm}$ of their noses, and then breathed 20 minutes through the nose. Glass containers with the same shape and color were pre-coded by the consultant pharmacist and was unknown to the researcher.

It was taught to mothers, if any abnormal signs (i.e., running nose, skin rash, itching, headache, burning eyes, and abdominal pain) appeared throughout the intervention period, the intervention should be stopped and recorded. Seven copies of the Rhodes nausea-vomiting questionnaire were given to the participants to fill at the end of each day of study. In addition, mothers completed the state anxiety scale after the last day of intervention (seventh day).

\section{Instruments}

The Rhodes nausea-vomiting index with a 5-point Likert-type questionnaire was used to measure nausea and vomiting. This tool has 8-item and three subscales (nausea, vomiting, and retching).

The questions measure levels and distress caused by these symptoms (Matthews et al., 2015). The questionnaire complete by selecting one option from the least or absent symptom (zero) to the worst- 
case (four). Therefore, the total scores range from 0 to 32. A score of 0 indicates no symptom, 1 to 8 mild, 9 to 16 moderate, and 17 to 32 severe symptoms (Hirose et al., 2020). Rhodes has created this index to measure nausea and vomiting symptoms associated with chemotherapy, also validated in studies of nausea and vomiting of pregnancy (Matthews et al., 2015). In Iran, its validity has been confirmed by the content validity method, and its reliability was calculated and confirmed using Cronbach's Alpha coefficient test $(a=0.8)$ (pakniat et al., 2018).

The State-Trait Anxiety Inventory (STAI) Scale (Spielberg) is used to assess anxiety. The STAI scale is a commonly used to measure two types of anxiety: state and trait anxiety. State anxiety (A-State) is a transitory emotional response to a specific situation accompanied by feeling tension and apprehension. The state anxiety scale consists of 20 self-descriptive statements, with each item scored on a 4-point Likert scale ranging from 1 to 4 . Thus, the total score ranges from 20 to 80 , where a higher score indicates higher anxiety. The reliability of the STAI scale in the Persian language was supported by a Cronbach's alpha coefficient of 0.9 (Afand et al., 2017).

\section{Statistical methods}

Descriptive statistics were used to describe the sample characteristics. The normality of quantitative data was evaluated using the Kolmogorov-Smirnov test. The Fisher and Chi-square tests were used to compare qualitative variables. The repeated measures analysis was utilized to compare the mean scores of the Rhodes index during the seven days of intervention. Paired and independent sample t-tests were used to find differences within and between the two groups. SPSS version 16 was used for the data analysis, and the $p<0.05$ was considered statistically significant.

\section{Results}

Of 72 mothers who participated in the study, 66 mothers were recruited into two groups: the Lavender and the control. Excluded cases were three participants due to irregular use of oil (one and two mothers in the Lavender and control group, respectively) and three participants for using other drugs (one and two mothers in the control and Lavender group, respectively) (Fig. 1).

There were no significant differences between the two groups in the demographic characteristics between two groups. Most of participants were primigravida (Table 1). The mothers' initial Rhodes index scores were similar ( $p=0.914$, Table 2). The comparison of mean scores of the Rhodes index between the two groups showed no significant differences except on day seven $(p=0.008)$ (Table 2$)$. In addition, the results obtained from repeated measures analysis indicated that the mean score of the Rhodes index was significantly decreased in the Lavender and control groups ( $p=0.0001$ and 0.004 , respectively) (Table 2). However, the decrease in the Lavender group was more apparent (Fig. 2). After seven days, the severity of nausea and vomiting were statistically significantly different between the two groups $(p=0.032)$ (Table $3)$. 
Seven days after the intervention, the mean scores and severity of MSA in mothers of the Lavender group were significantly lower than the control group ( $p=0.012$ and $p=0.027$, respectively) (Tables 4 and 5 ). After the intervention, the mean scores of MSA has significantly decreased in two groups $(p<0.0001)$ (Table 4).

\section{Discussion}

We studied the effect of aromatherapy using Lavender oil and those of a placebo. Our results showed that the mean score and severity of nausea, vomiting, and anxiety in the Lavender group were significantly less than the control group after seven days. In the current study, NVP was evaluated from the first to the seventh day of the intervention. There was a noticeable significant statistical difference between the two groups in the total Rhodes score on the seventh day of the intervention. However, the Rhodes nausea-vomiting index score decreased over time in both groups. However, the decrease in the Lavender group was more manifest than in the control group. This decrease in the control group might be due to the placebo effect in such studies.

In some studies, the effect of Lavender oil on nausea and vomiting in pregnancy has been reported (Rahayu \& Sugita, 2018, Ghani \& Ibrahim, 2013). In one, Lavender oil was more effective than Ginger on the frequency of nausea and vomiting (Rahayu \& Sugita, 2018). In another study, on the third day of the intervention, the combination of Lavender and Peppermint reduced episodes of nausea and vomiting (Ghani \& Ibrahim, 2013). It is noticeable that reports of oils on both NVP and anxiety in pregnant women are limited. In one study, inhalation of Mint aroma significantly decreased nausea and vomiting of pregnancy on the fifth day of the intervention, but not on state anxiety level (Amzajerdi et al., 2019).

The current study revealed that aromatherapy with Lavender oil significantly reduced the severity and the mean score of state anxiety in pregnant women. The positive effect of Lavender alone and Lavender with foot-bath have been reported on anxiety level, stress, and depression (Effati-Daryani et al., 2015). In two studies, Lavender oil was one of the three possible oils to choose for inhalation in pregnancy. In one study, which started at 28 weeks of pregnancy, aromatherapy had no significant effect on state anxiety but significantly reduced trait anxiety (Igarashi and Fujita, 2010). In another, short-term aromatherapy with essential oils significantly improved the tension-anxiety and anger-hostility scores for pregnant women (Igarashi, 2013). One study found that aromatherapy massage using Lavender oil could significantly decrease stress and enhance immune function in pregnant women (Chen et al., 2017). Lavender aromatherapy also effectively reduced the levels of norepinephrine in women with postpartum blues (Amin et al., 2020). In addition, aromatherapy with Lavender improved anxiety status and decreased cortisol secretion from the adrenal gland during labor in nulliparous women (Mirzaei et al., 2009). In one meta-analysis, Lavender aromatherapy positively relieved anxiety and decreased cortisol levels (Kang et al., 2019).

Lavender is the most popular oil used during pregnancy (Bishop et al., 2011). Lavender oil is an aromatic herbal extract with antibacterial, antifungal, carminative (smooth muscle relaxants), sedative, and 
antidepressant properties (Hedaoo et al., 2019, Amin et al., 2020). It is used in pharmacy, phytotherapy, and aromatherapy (López et al., 2017). The mechanism of action of Lavender oil is not specified. Some studies showed that it exhibits anticholinergic, antihistaminic, and anti-inflammatory activities. These effects are similar to those of the antiemetic drugs that are commonly used (Karaman et al., 2019). Traditionally, Lavender as an herbal remedy has been associated with anxiolytic properties (Donelli et al., 2019). Studies approve the high linalool and linalyl acetate content in this medicinal plant (López et al., 2017, Amin et al., 2020). Both sedative and anxiolytic components of Lavender are responsible for the pharmacological effects (López et al., 2017, Donelli et al., 2019). The stimulation of olfactory receptor cells can explain the main mechanism in the nasal epithelium (Amin et al., 2020). It binds to the specific receptors of sensorial nasal neurons connected to the olfactory bulbs in the limbic system and stimulates smell and emotion (Di Vito et al., 2021).

The optimal strategies for pregnant women involve natural, harmless, and safe interventions, such as complementary therapies. For example, as a low-cost complementary medicine with fewer complications and non-invasive forms of treatment, aromatherapy is used to improve an individual's psychological health and well-being (Chen et al., 2017, Amin et al., 2020). So it is better for aromatherapy in pregnant women to be at the top of research programs.

\section{Conclusions}

The current study results showed that aromatherapy with Lavender oil could reduce nausea, vomiting, and anxiety in pregnant women. Due to the interest of pregnant women in complementary medicine and considering the simplicity and cost-effectiveness of this intervention without side effects, caregivers can advise using Lavender to eligible pregnant women. Using such methods may improve pregnant women's quality of life and efficiency in such a crucial period. However, further studies with more extended intervention periods are necessary to confirm these results.

\section{Limitations}

The impossibility of blinding for participants due to the nature of direct inhalation aromatherapy was a significant limitation.

\section{Declarations}

\section{Contributions of authors}

Azam Amzajerdi and Maryam Keshavarz participated in the study's design, acquisition, and analysis of the data and writing of the manuscript. Ali Montazeri participated in the design of the study, analysis of data. Dr. Bekhradi for formulating and supplying the aromatherapy oils used in the study. All authors read and approved the final version of the submitted manuscript.

\section{Ethics}


The ethical committee approved the study of TUMS with ethical code number 2478 . The study was registered in the Iranian Clinical Trial Registry (IRCT) with the number IRCT201306082324N12. All participants obtained the written informed consent. They were informed that their names and characteristics would not be published.

\section{Compliance with ethical standards}

All procedures performed in this study were under the ethical standards of Ethical Committee of TUMS.

\section{Funding}

The Research Committee of TUMS funded this study.

\section{Acknowledgments}

The authors are grateful to all pregnant women for their participation in this study. This study was submitted as partial fulfillment of the MSc thesis of midwifery which TUMS supported.

\section{References}

1. ACOG Practice Bulletin No. 189: Nausea and Vomiting of Pregnancy, Obstetrics \&Gynecology: January 2018, 131(1), e15-e30. doi:10.1097/aog.0000000000002456

2. Matthews A, Haas DM, O’Mathúna DP, Dowswell T. Interventions for nausea and vomiting in early pregnancy. Cochrane Database of Systematic Reviews. 2015; 9.

3. Heitmann K, Holst L, Lupattelli A, Maltepe C, Nordeng H. Treatment of nausea in pregnancy: a crosssectional multinational web-based study of pregnant women and new mothers. BMC Pregnancy and Childbirth. 2015; 15(1):1-13.

4. Gray MF, Hsu C, Kiel L, Dublin S. Getting through the day: a pilot qualitative study of US women's experiences making decisions about anti-nausea medication during pregnancy. BMC pregnancy and childbirth. 2018 Dec; 18(1):1-8.

5. Bustos M, Venkataramanan R, Caritis S. Nausea and vomiting of pregnancy-What's new? Autonomic Neuroscience: Basic and Clinical. 2017; 202:62-72.

6. Schrager NL, Adrien N, Werler MM, Parker SE, Van Bennekom C, Mitchell AA. Trends in first-trimester nausea and vomiting of pregnancy and use of select treatments: Findings from the National Birth Defects Prevention Study. Paediatr Perinat Epidemiol. 2021;35(1):57-64.

7. Parker SE, Van Bennekom C. Anderka M, Mitchell AA. Ondansetron for Treatment of Nausea and Vomiting of Pregnancy and the Risk of Specific Birth Defects. Obstetrics and Gynaecology. 2018 Aug $1 ; 132(2): 385-94$.

8. Ravid E, Salzer L, Arnon L, Eisner M, Wiznitzer A, Weller A, Koren L, Hadar E. Is there an association between maternal anxiety propensity and pregnancy outcomes? BMC pregnancy and childbirth. 2018 Dec; 18(1):1-6. 
9. Dennis CL, Falah-Hassani K, Shiri R. Prevalence of antenatal and postnatal anxiety: systematic review and meta-analysis. The British Journal of Psychiatry. 2017 May; 210(5):315-23.

10. Di Vito M, Cacaci M, Martini C, Barbanti L, Mondello F, Sanguinetti M, Mattarelli P, Bugli F. Is aromatherapy effective in obstetrics? A systematic review and meta-analysis. Phytotherapy Research. 2021 May; 35(5):2477-86.

11. Bishop JL, Northstone K, Green JR, Thompson EA. The use of complementary and alternative medicine in pregnancy: data from the Avon Longitudinal Study of Parents and Children (ALSPAC). Complementary therapies in medicine. 2011 Dec 1; 19(6):303-10.

12. Ali B, Al-Wabel NA, Shams S, Ahamad A, Khan SA, Anwar F. Essential oils used in aromatherapy: A systemic review, Asian Pacific Journal of Tropical Biomedicine. 2015 Aug 1;5(8):601-11.

13. Hedaoo SA, Chandurkar PA. A Review on Aromatherapy. World Journal of Pharmaceutical Research. 2019 Mar 28;8(7):635-51.

14. Karaman S, Karaman T, Tapar H, Dogru S, Suren M. A randomized placebo-controlled study of aromatherapy for the treatment of postoperative nausea and vomiting. Complementary therapies in medicine. 2019 Feb 1; 42:417-21.

15. Ain A, Agung DG, Yunitasari E. Aromaterapi Lavender dalam Upaya menurunkan Nausea dan Vomiting Pasien Kanker Payudara yang Menjalani Kemoterapi di RSUD Dr. Soetomo Surabaya. Jurnal Ners dan Kebidanan (Journal of Ners and Midwifery). 2019 Dec 5; 6(3):401-7.

16. Amirhosseini M, Dehghan M, Shahrbabaki PM, Pakmanesh H. Effectiveness of Aromatherapy for relief of pain, nausea and vomiting after percutaneous nephrolithotomy: A randomized controlled trial. Complementary medicine research. 2020;27(6):440-48.

17. Hodge NS, McCarthy MS, Pierce RM. A prospective randomized study of the effectiveness of aromatherapy for relief of postoperative nausea and vomiting. Journal of Peri Anesthesia Nursing. 2014Feb 1; 29(1):5-11.

18. Rahayu RD, Sugita S. Efektivitas Pemberian Aromaterapi Lavender Dan Jahe Terhadap Penurunan Frekuensi Mual Muntah Pada Ibu Hamil Trimester I Di BPM Trucuk Klaten. Jurnal Kebidanan Dan Kesehatan Tradisional. 2018 Mar 8;3(1):19-26.

19. Ghani RM, Ibrahim AT. The effect of aromatherapy inhalation on nausea and vomiting in early pregnancy: A pilot randomized controlled trial. J Natl Sci Res .2013;3(6):10-22.

20. López V, Nielsen B, Solas M, Ramírez MJ, Jäger AK. Exploring pharmacological mechanisms of lavender (Lavandula angustifolia) essential oil on central nervous system targets. Frontiers in pharmacology. 2017 May 19;8:280.

21. Arslan I, Aydinoglu S, Karan NB. Can lavender oil inhalation help to overcome dental anxiety and pain in children? A randomized clinical trial. European Journal of Pediatrics. 2020Feb 6;1-8.

22. Abbaszadeh R, Tabari F, Asadpour A. The effect of Lavender aroma on anxiety of patients having bone marrow biopsy. Asian Pac J Cancer Prev. 2020Mar;21(3):771-75.

23. Karaman T, Karaman S, Dogru S, et al.Evaluating the efficacy of lavender aromatherapy on peripheral venous cannulation pain and anxiety: A prospective, randomized study. Complementary therapies in 
clinical practice. 2016May 1;23,64-68.

24. Hosseini S, Heydari A, Vakili M, Moghadam S, Tazyky S. Effect of lavender essence inhalation on the level of anxiety and blood cortisol in candidates for open-heart surgery. Iran J Nurs Midwifery Res. 2016 Jul-Aug;21(4):397-401.

25. Conrad P, Adams C. The effects of clinical aromatherapy for anxiety and depression in the high risk postpartum woman-a pilot study. Complementary Therapies in Clinical Practice. 2012Aug $1 ; 18(3) ; 164-8$.

26. Amin E, Rahardjo B, Kusworini. Aromatherapy oils of lavender (Lavandula angustifolia) inhalance reduced norepinephrine levels of woman with postpartum blues based on Edinburgh postpartum depression scale. InAIP Conference Proceedings 2020 Apr 21 (Vol. 2231, No. 1, p. 040065). AIP Publishing LLC.

27. Mirzaei F, Keshtgar S, Kaviani M, Rajaeifar AR. The effect of lavender essence smelling during labor on cortisol and serotonin plasma levels and anxiety reduction in nulliparous women. Journal of Kerman University of Medical Sciences. 2009 Jan 1;16(3):245-54.(persian)

28. Kang HJ, Nam ES, Lee Y, Kim M. How strong is the evidence for the anxiolytic efficacy of lavender?: systematic review and meta-analysis of randomized controlled trials. Asian nursing research. 2019 Dec 1;13(5):295-305.

29. Igarashi T, Fujita M. Effects of aromatherapy for self-care during pregnancy. J.Nara Med. Assoc. 2010;61:101-112.

30. Igarashi T. Physical and psychologic effects of aromatherapy inhalation on pregnant women: a randomized controlled trial. The Journal of Alternative and Complementary Medicine. 2013 Oct 1;19(10):805-10.

31. Chen PJ, Chou CC, Yang L, Tsai YL, Chang YC, Liaw JJ. Effects of aromatherapy massage on pregnant women's stress and immune function: A longitudinal, prospective, randomized controlled trial. The Journal of Alternative and Complementary Medicine. 2017 Oct 1;23(10):778-86.

32. Effati-Daryani F, Mohammad-Alizadeh-Charandabi S, Mirghafourvand M, Taghizadeh M, Mohammadi A. Effect of lavender cream with or without foot-bath on anxiety, stress and depression in pregnancy: a randomized placebo controlled trial.Journal of caring sciences. 2015 Mar;4(1):63.

33. Köken G, Yilmazer M, Cosar EN, Sahi` n FG, Cevri`oglu S, Geci` ci` Ö. Nausea and vomiting in early pregnancy: relationship with anxiety and depression. Journal of Psychosomatic Obstetrics \& Gynecology. 2008 Jan 1;29(2):91-5.

34. Nikibakhsh A, Neisanisamani L, Keshavarz M, Hosseini F. Induce and severity of nausea and vomiting during pregnancy and its association with anxiety and depression in pregnant women. Iran J Nurs. 2016;(101):1-11. (Persian)

35. Beyazit F, Sahin B. Effect of nausea and vomiting on anxiety and depression levels in early pregnancy. The Eurasian journal of medicine. 2018 Jun;50(2):111.

36. Amzajerdi A, Keshavarz M, Montazeri A, Bekhradi R. Effect of mint aroma on nausea, vomiting and anxiety in pregnant women. Journal of family medicine and primary care.2019 Aug;8(8):2597. 
37. Hirose M, Tamakoshi K, Takahashi Y, Mizuno T, Yamada A, Kato N. The effects of nausea, vomiting, and social support on health-related quality of life during early pregnancy: A prospective cohort study. Journal of Psychosomatic Research. 2020 Sep 1;136:110168.

38. Pakniat H, Memarzadeh MR, Azh N, Mafi M, Ranjkesh F. Comparison of the effect of chamomile, Ginger and vitamin B6 on treatment of nausea and vomiting in pregnancy: a randomized clinical trial. The Iranian Journal of Obstetrics, Gynecology and Infertility. 2018 Oct 23;21(8):47-54. (Persian)

39. Afand N, Keshavarz M, Fatemi NS, Montazeri A. Effects of infant massage on state anxiety in mothers of preterm infants prior to hospital discharge. Journal of clinical nursing. 2017 Jul;26(1314):1887-92.

40. Donelli D, Antonelli M, Bellinazzi C, Gensini GF, Firenzuoli F. Effects of lavender on anxiety: a systematic review and meta-analysis. Phytomedicine. 2019 Dec 1;65:153099.

\section{Tables}

Due to technical limitations, Tables are only available as a download in the Supplemental Files section.

\section{Figures}




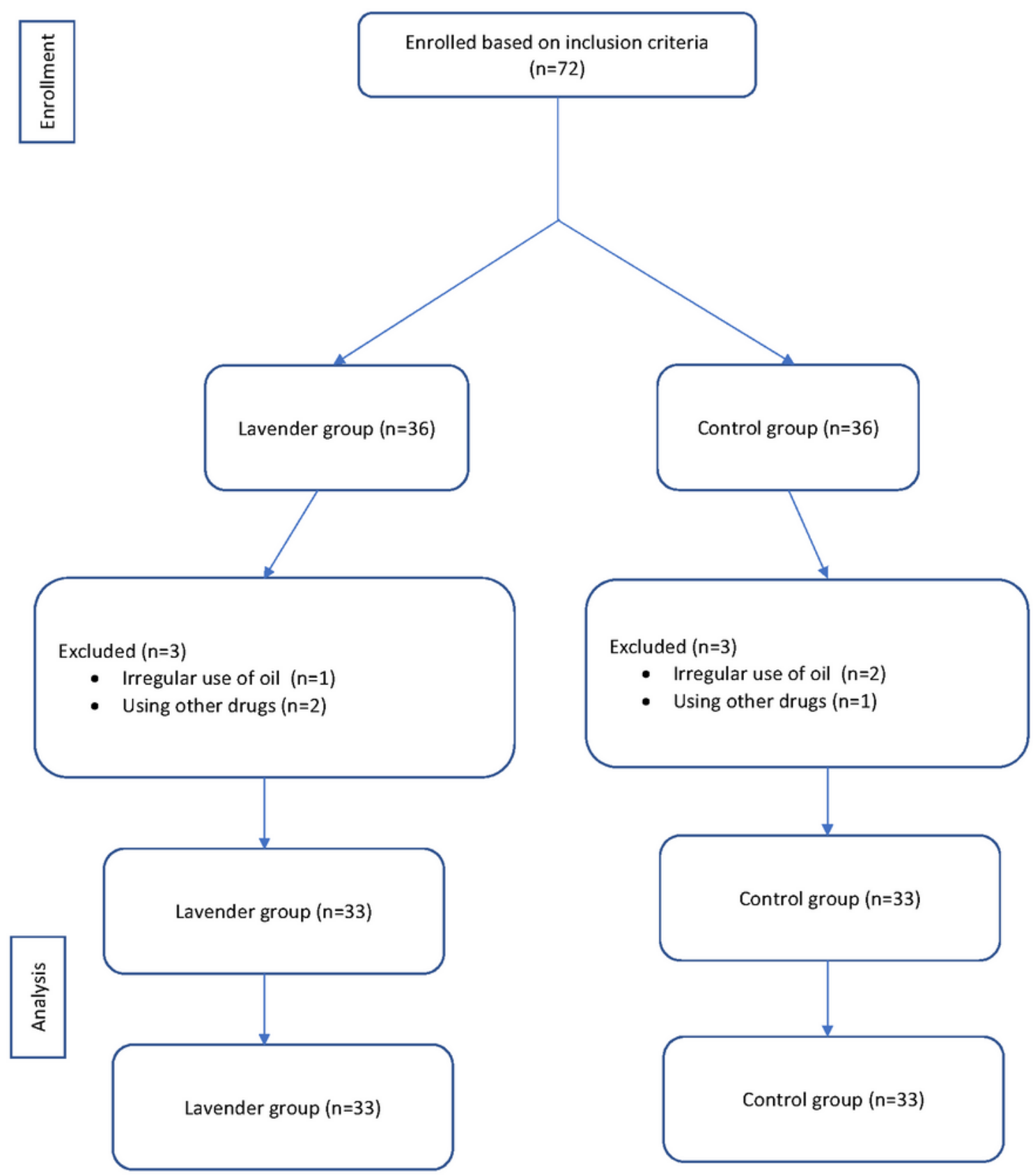

Figure 1

Consort flow diagram. 


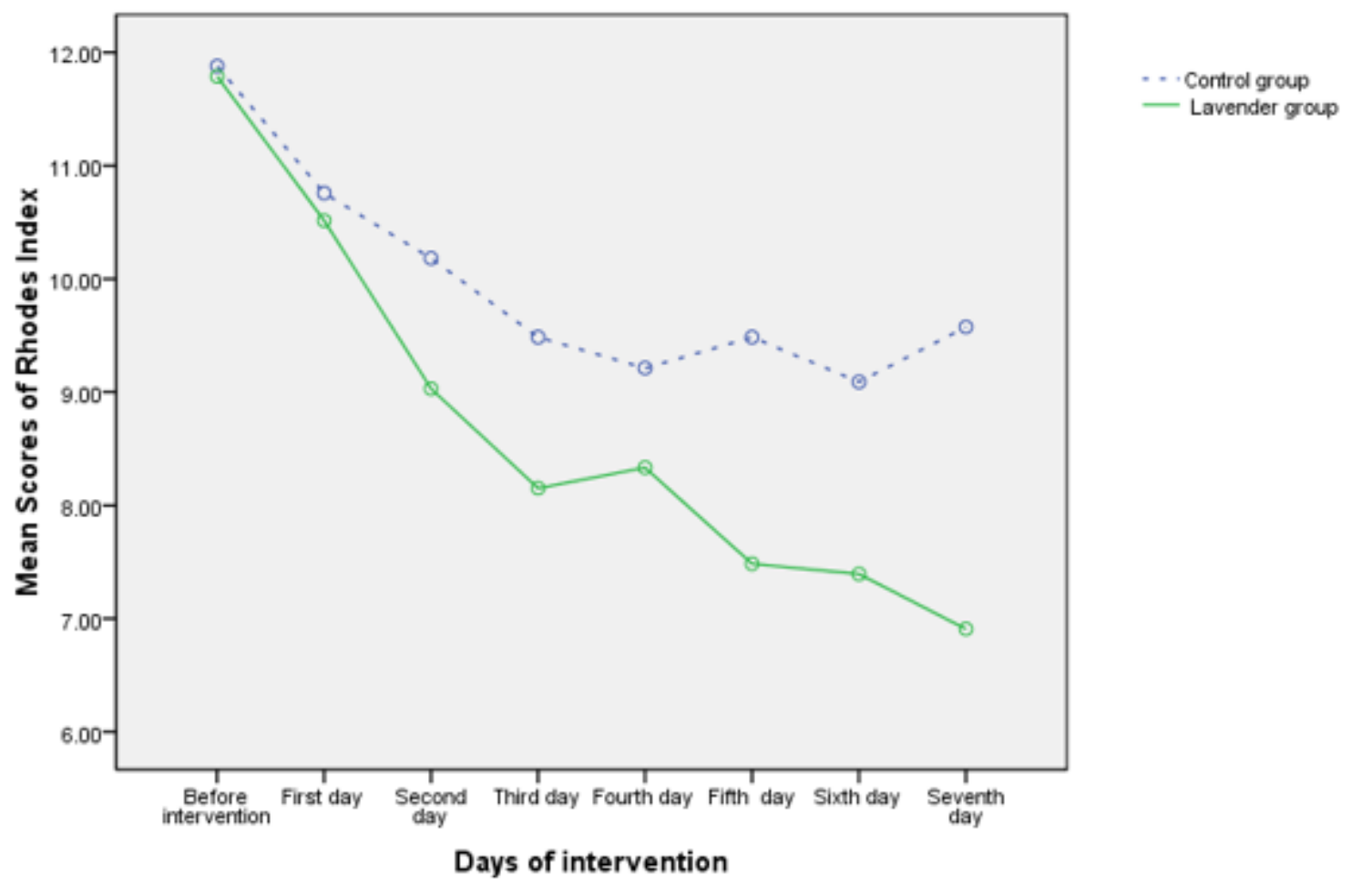

Figure 2

The mean scores of Rhodes index before and during the seven days of the intervention in the two groups.

\section{Supplementary Files}

This is a list of supplementary files associated with this preprint. Click to download.

- Tables.pdf 